\title{
QUANDO A CASA É A PRISÃO: UMA ANÁLISE DE DECISÕES DE PRISÃO DOMICILIAR DE GRÁVIDAS E MÃES APÓS A LEI 12.403/2011
}

\author{
Ana Gabriela Braga ${ }^{1}$ \\ Naila Ingrid Chaves Franklin ${ }^{2}$
}

\begin{abstract}
Resumo
O presente artigo é fruto de pesquisa financiada pela FAPESP e teve por objeto de estudo e análise a maneira como as questões relacionadas à efetivação de direitos de presas grávidas e mães estão sendo tratadas pelo sistema de justiça criminal. Considerando que o ordenamento jurídico pátrio regula de forma especifica os direitos materno-infantis, buscamos entender, por meio da análise de acórdãos do TJ/SP, como tem sido a efetivação de direitos de gestantes e mães presas pelos julgadores. $\mathrm{O}$ foco da pesquisa foi a aplicação do instituto da prisão domiciliar trazido pela lei 12.403/2011 em casos de gestação e maternidade. A análise dos acórdãos permitiu a conclusão de que a dissociação entre a mulher criminosa - principalmente a traficante - e a maternidade produz uma discriminação negativa, terminando por influenciar na negativa da concessão de institutos benéficos trazidos pela lei em questão.
\end{abstract}

Palavras-chave: encarceramento feminino- prisão domiciliar- Lei 12.403/2011-gestantes - mães.

\section{INTRODUÇÃO}

O presente artigo, escrito em co-autoria de orientanda com orientadora, é fruto de pesquisa financiada pela Fundação de Amparo à Pesquisa do Estado de São Paulo (FAPESP) e indicada à publicação. A pesquisa teve por objetivo compreender, a partir da resposta jurisdicional, os discursos em torno da efetivação dos direitos e as representações em torno da "mulher mãe que transgride a norma penal". Essa mulher é, sobretudo, uma mulher que rompe com os ideais de feminilidade tradicionais ao praticar uma conduta que tradicionalmente se caracterizou como masculina, em um espaço amplamente dominado por homens, como é tráfico de drogas, principal crime pelo qual as mulheres estão presas atualmente.

\footnotetext{
${ }^{1}$ Doutora em Direito Penal e Criminologia pela Universidade de São Paulo. Professora da Faculdade de Ciências Humanas e Sociais da UNESP- campus Franca. Coordena o NEPAL (Núcleo de Estudos e Pesquisa em Aprisionamentos e Liberdades), o Centro Interdisciplinar de Estudos em Gênero (CIEPEDIG), além do projeto de Extensão CADEIA na Cadeia Feminina de Franca. Pesquisadora do NADIR - Núcleo de Antropologia do Direito (FFLCH- USP) e do Núcleo de Pesquisa do IBCCRIM. Coordena a pesquisa "Diagnóstico dos serviços prisionais no Brasil" no âmbito do mesmo projeto e em parceria com o DEPEN. Email: agabriela@gmail.com

${ }^{2}$ Mestranda em Direito pela Universidade de Brasília (UnB). E-mail: naila.franklin@gmail.com
} vol.09, nº. 01, Rio de Janeiro, 2016.pp. 349-375 
Contudo, também é imprescindível que se visualize de que não se trata de qualquer mulher a que enfocamos neste trabalho: trata-se de mulheres pobres, negras e jovens. Esse fator deriva dos dados que tomamos como base: dados do Departamento Penitenciário Nacional DEPEN- (BRASIL, 2011), que demonstram que a mulher encarcerada e mãe não é qualquer mulher, mas que reúne, em sua grande maioria, essas características que são essenciais para compreender a vulnerabilidade que possuem quanto à seleção das instâncias de controle formal do Estado penal.

Nesse contexto, buscamos saber: como o sistema de justiça criminal trata das mulheres mães que transgrediram a norma penal e foram selecionadas pelas instâncias de controle formal do Estado? Será que os julgadores são sensíveis a essas questões e viabilizam, no âmbito processual, a concessão de mecanismos benéficos a estas mulheres para que possam exercer a maternidade de forma plena? Ou será que fatores que são intrínsecos à vida dessas mulheres podem influenciar na tomada da decisão dos julgadores, de forma negativa? Será que há uma discriminação negativa da mulher nessas decisões?

O objeto do presente estudo, a partir do qual se propõe os questionamentos acima, é composto pelas decisões do Tribunal de Justiça de São Paulo (TJ/SP) que versavam sobre pedidos de prisão domiciliar para presas grávidas e mães recentes, conforme a possibilidade trazida pela lei de medidas cautelares (lei 12.403/2011). Para alcançar os objetivos propostos, optamos pela metodologia empírica de abordagem qualitativa. A escolha metodológica foi motivada pela certeza de que uma análise exclusivamente teórica não responderia às questões ora levantadas, e pela opção de analisar as palavras e sentidos do fazer justiça.

O recorte temporal da pesquisa compreendeu o período de julho de 2011 (mês de entrada em vigor da lei) até dezembro de 2013 (de modo a limitar o volume excessivo de dados). Esse recorte contribuiu para análise do impacto da chamada "lei das cautelares" na situação jurídica da mulher presa, de modo a dialogar com outras pesquisas recentes acerca da prisão provisória no Brasil (JESUS et all., 2011; LEMBRUGER et all., 2011; IPEA, 2015; ITT et all., 2012; SOU DA PAZ, 2012). Um dos efeitos esperados quando da promulgação da Lei 12.403 em 2011 era reduzir o número de presos preventivos- que aquela altura já alcançava índices alarmantes. Além de ampliar as possibilidades de conversão em prisão domiciliar (art. 318 CPP), a reforma trouxe uma ampliação das cautelares com um rol com nove medidas diversas da prisão (artigo 319 CPP).

Com a finalidade de filtrar as decisões de segundo grau relativas ao pedido de domiciliar decorrente da maternidade, utilizou-se a ferramenta de busca do site do Tribunal de Justiça de São Paulo² com as seguintes expressões de busca: "prisão domiciliar" e "gravidez". Nesse recorte, foram encontrados 120 acórdãos que continham as expressões que interessam à presente; destes apenas 80 estavam circunscritas ao lapso temporal selecionado. 
Da leitura e análise dos acórdãos algumas questões se fizeram centrais, as quais reunirmos em torno de

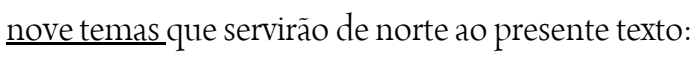

1. Maternidade e crime no discurso judicial;

2. Tráfico de drogas e mulheres;

3. Interesse superior da criança versus interesse inferior da mulher;

4. Condições materiais versus plano formal;

5. Gravidez na prisão: gravidez de risco?;

6. Tempo de gestação e tempo da justiça

7. Prova idônea das condições legislativas;

8. O poder dever: a faculdade do julgador;

9. Prisão domiciliar versus outras medidas cautelares.

Ao final conclui-se que a lei não é cumprida por múltiplos fatores, mas a discriminação negativa que incide sobre o gênero feminino, fazendo com que as figuras de "mãe" e "criminosa" sejam socialmente irreconciliáveis são aspectos centrais para entender as causas da não concessão da prisão domiciliar como forma de possibilitar uma maternidade sadia a estas mulheres.

\section{MATERNIDADE E CRIME NO DISCURSO JUDICIAL}

Se o tema da maternidade está intrinsecamente conectado com o debate de gênero, nos julgamentos criminais que envolvem mulheres gestantes ou mães recentes (com filhos recém-nascidos), esta conexão fica mais evidente. No universo da pesquisa identificamos duas tendências no julgamento de mulheres gestantes ou puérperas presas: ora os julgadores creditam à maternidade uma espécie de "salvação moral", uma forma de sair do mundo do crime, e portanto, reconhecem os direitos de maternagem; ora denegam seus pedidos principalmente em casos de mães com filhos menores (mas não bebês) e não-gestantes - baseados na crença de que a conduta "criminosa" da ré não condiz com a de uma mãe que é imprescindível aos cuidados de seu filho.

Tendo como premissa que a mulher que pratica uma conduta problemática definida como crime rompe drasticamente com os papéis sociais de gênero que the são destinados, a mulher criminosa e mãe se encontra em um dualismo: por um lado, ao transgredir a norma penal adotou uma conduta não esperada socialmente. Por outro, ao ser mãe retorna às expectativas sociais que lhe são depositadas.

O presente trabalho parte do pressuposto da existência de maternidades mais valorizadas do que outras frente à sociedade, eis que considera a existência da construção de um ideal de mulher que poderia exercer a maternidade de forma socialmente legítima, em detrimento de outras, de acordo com o conceito de hierarquias reprodutivas, segundo o qual a somatória e a interação de diferentes aspectos da mulher determinam o grau de vol.09, nº. 01, Rio de Janeiro, 2016.pp. 349-375 
aceitação social de uma determinada maternidade (MATTAR, 2011, p. 27). Esses aspectos incluem categorias como raça, classe, sexualidade, idade, etc, aspectos que irão produzir maternidades ilegítimas, subalternas e marginais frente a outras. E, tratando-se de um contexto específico de exclusão, o cárcere, em que as mulheres estão custodiadas pelo Estado, a regulação da maternidade transpassa diretamente o Estado, mais especificamente, por meio dos atores do sistema de justiça criminal, os quais são responsáveis pelo destino e pelo controle da maternidade dessas mulheres.

O julgamento de mulher pelo sistema de justiça aciona uma dupla punição: a punem por violar a regra penal, mas sobretudo, pela ruptura com as expectativas sociais. Nesse cenário, a maternidade é vista como uma forma da mulher desviante se aproximar da normalidade, a partir de uma representação de maternidade ligada às condutas associadas ao "feminino" (preocupação com as crianças, comportamento passivo, ausência de conduta criminosa), e portanto, distante da masculinidade atribuída ao mundo do crime.

Apresentaremos a seguir alguns exemplos que ilustram esses dois tipos de conexão identificados no campo de pesquisa: o primeiro, da maternidade como salvação da criminosa, e, o segundo, do crime como elemento contaminador da pureza que envolve a maternidade. Os casos foram retratados a partir das informações obtidas nos acórdãos, de início apresentamos um curto resumo do caso e em seguida argumentos utilizados pelos desembargadores. Na maioria do texto discutimos o tema a partir de trechos de acórdãos, em outros momentos, achamos necessário contextualizar a história da mulher e as decisões, então o apresentamos no formato de casos. No total apresentamos neste artigo trechos de 18 decisões e 5 casos que julgamos emblemáticos para discutir desde uma perspectiva de gênero, o tema da maternidade e prisão domiciliar.

\section{TRAFICO DE DROGAS E MULHERES}

De acordo com o Departamento Penitenciário Nacional (BRASIL, 2011), 60\% das mulheres estão presas por crime de tráfico de drogas, uma das chaves para compreender esse dado está na relação entre a economia da droga e economia doméstica, o papel normalmente destinado à mulher permite que ela siga com os cuidados com a casa e com os filhos e filhas, e ao mesmo, tempo garanta seu sustento. Essa relevante porcentagem, e o incremento da população prisional feminina como fenômeno mundial, tem impulsionado inúmeras pesquisas de fôlego estão sendo realizadas para que se investigasse o papel das mulheres no tráfico de drogas e sua relação com o sistema de justiça criminal, com um enfoque na questão de gênero, tais como CHERNICHARO et all, 2014. HELPES, 2014; MOURA, 2014; SOARES et all, 2005.

A maior parte das mulheres detida responde por crime de tráfico. Contudo, é de se questionar qual o papel ocupado por esta mulher nas redes do mercado ilícito e na sociedade. Em uma pesquisa realizada no presídio feminino do Ceará, MOURA (2014) entrevistou as encarceradas que estavam presas por tráfico de drogas, sendo vol.09, n. 01, Rio de Janeiro, 2016.pp. 349-375 
que constatou que, dentre os principais motivos para que as mulheres adentrassem no mercado de drogas estão o desemprego e a miséria, além da falta de políticas públicas para satisfazer as necessidades das mulheres e de suas famílias, além da possibilidade de colaborar e gerar rendimentos para o grupo familiar. Além disso, a mesma autora ressaltou que as mulheres, quando indagadas sobre o papel que ocupavam na rede de tráfico estavam inseridas em papéis subalternos, como as chamadas "mulas" e "aviões", atividades que envolvem pouco ganho de capitalhipótese confirmada também por SOARES e ILGENFRITZ (2005).

As "facilidades" da economia do tráfico somadas às posições vulneráveis que as mulheres geralmente ocupam no comércio de drogas contribuiu para a criminalização dessas mulheres, que em sua maioria, com baixíssimo grau de escolaridade, estão à margem do mercado formal de trabalho. A dinâmica do tráfico de drogas em contato com a política altamente repressiva do Estado contribui significativamente para o aumento do encarceramento feminino nos últimos anos. Logo, poderíamos afirmar que sob esse aspecto e "neste contexto, as mulheres são atingidas de maneira muito expressiva, revelando que a guerra contra as drogas é também uma guerra contra as mulheres" (CHERNICHARO et all, 2014, p. 16).

Diversas personagens contribuem para a construção e propagação dessa política altamente repressiva contra as drogas. No caso específico dos desembargadores, com a análise dos acórdãos nesta pesquisa, mostramos que os mesmos compõem a teia punitivista, reforçando a ideia do tráfico como um crime que deve ser tratado de forma altamente repressiva, fazendo julgamentos altamente descolados da realidade social do tráfico de entorpecentes e das mulheres que nele se imiscuem.

Apesar da presente pesquisa não ter um recorte específico em relação às drogas, o universo selecionado para a análise confirma a estatística: a imensa maioria dos acórdãos analisados dizia respeito a acusações de tráfico de drogas. Este cenário faz com que a discussão das drogas, e as representações em torno dessa temática, ganhe importância em qualquer discussão sobre encarceramento feminino.

De forma geral, os julgadores utilizaram a equiparação legal do tráfico de drogas como crime hediondo para atestar sua gravidade e justificar a negação da prisão domiciliar ou outros direitos de execução penal. A retórica da hediondez do tráfico legitima o encarceramento, mesmo que a lei dos crimes hediondos não vede a liberdade provisória, os juízes e juízas a vedam na prática. Como nas duas decisões a seguir:

\section{Decisão 01}

A Lei Maior tornou inafiançável o crime de tráfico de entorpecentes, obstou-lhe a liberdade provisória, ainda mais quando facilitada pela dispensa da garantia real (...). Não bastasse, o crime imputado a ora paciente é grave. Não porque o tráfico de entorpecentes seja abstratamente considerado como delito que atinge muito severamente a paz social, fomentando outros ilícitos e destruindo vidas e famílias, mas porque o comércio de entorpecentes atribuído à ora paciente é de grande proporção e seu papel na organização vol.09, nº. 01, Rio de Janeiro, 2016.pp. 349-375 
criminosa, segundo a acusação que lhe recai, é importante. (BRASIL. Tribunal de Justiça de São Paulo. Habeascorpus. Tráfico de drogas. Habeas-corpus n0226559-30.2011.8.26.0000, 6ª̂amara de Direito Criminal, São Paulo, SP, 20 de janeiro de 2012).

\title{
Decisão 02
}

O crime em questão é gravíssimo e traz grande preocupação e prejuízo à sociedade, destruindo lares e subjugando a juventude, além do que é equiparado aos hediondos e, apesar de atualmente ser permitida a liberdade provisória em casos excepcionais, cada hipótese deve ser examinada com cuidado e, no presente, entendo ausentes os requisitos para tal; (...). Acrescente-se também que eventuais circunstâncias pessoais da paciente acabam por se tornar insignificantes em face da gravidade do delito, sendo de rigor a manutenção de sua prisão. (BRASIL. Tribunal de Justiça de São Paulo. Habeas corpus. Tráfico de drogas. Habeas-corpus no 0243640-55.2013.8.26.0000, da 15ª Câmara de Direito Criminal, São Paulo, SP, 21 de fevereiro de 2013).

Ainda nas decisões favoráveis à concessão de prisão domiciliar de mulheres processadas por crimes relacionados às drogas, observou-se que havia uma preocupação de se ressalvar que aquela medida era excepcional, dadas as circunstâncias do caso, eis que o tráfico é considerado crime grave e, que por si só, autorizaria a prisão preventiva com base no art. 312 do $\mathrm{CPP}^{3}$, como no exemplo abaixo:

\section{Decisão 03}

\begin{abstract}
Se não bastasse, é de se ter presente que ela responde por crime grave - tráfico de entorpecentes - e que, sabido, à sociedade, é fomento da prática de crimes gravíssimos como furtos, roubos, homicídios e latrocínios, provocando pânico e temeridade social, a recomendar a observância das medidas assecuratórias da aplicação da lei penal, não sendo recomendado que responda em liberdade o processo (...).Demais disso, embora controversa a concessão de liberdade provisória aos acusados pela prática do crime previsto no artigo 33, caput, da Lei n. $11.343 / 06$, ressalta-se, todavia, que esta não é a hipótese aqui tratada. O que ocorre in casu é a manutenção da prisão preventiva, que pode ser cumprida em prisão domiciliar. (BRASIL. Tribunal de Justiça de São Paulo. Habeas corpus. Tráfico de drogas. Habeas-corpus no 0206397-77.2012.8.26.0000, da 12a Câmara de Direito Criminal, São Paulo, SP, 17 de dezembro de 2012).
\end{abstract}

Nestas decisões, fica evidenciado o lugar oposto reservado à mãe e a criminosa e que, independente da decisão final, a gravidade do tráfico sempre é reafirmada, em qualquer circunstância. A seguir, passamos a narrar 3 casos que ilustram esses argumentos.

\section{Caso 1}


Mulher acusada de crime de tráfico de drogas - maconha - e, conforme esclarecimentos da defesa era primária e mãe de 04 filhos menores de idade, sendo um deles portador de necessidades especiais, assim pede a prisão domiciliar com base no art. 318 inc. IV do Código de Processo Penal. Os desembargadores entenderam que o fato do crime imputado à paciente ser o tráfico de drogas deslegitimava o seu pedido, pois, ao traficar, não se importou com inúmeros filhos que se tornam usuários de drogas, como se aponta a seguir:

Aliás, o fato de ser mãe deveria ter servido a paciente de desestímulo a prática da traficância, colocando-se no lugar da mãe que tem seu filho envolvido com droga tão nefasta por ela comercializada, o que, entretanto, não ocorreu. Se a condição de mãe não impediu que a paciente praticasse crime tão nocivo a tantos filhos, tampouco deve servir de óbice à sua prisão, se presentes os requisitos ensejadores da prisão preventiva e não estando cabalmente demonstrado que a paciente é imprescindível aos cuidados do filho. (BRASIL. Tribunal de Justiça de São Paulo. Habeas corpus. Tráfico de drogas. Habeas-corpus nº. 0210976-68 2012.8.26.0000, da 4a Câmara de Direito Criminal, São Paulo, SP, 19 de março de 2013).4

Neste acórdão, fica evidente a dissociação entre a figura da criminosa/traficante com a figura da mãe, como se o envolvimento com o crime de tráfico de drogas já denunciasse, por si, uma maternidade irresponsável, quando se discute que justamente o que leva a maior parte das mulheres ao tráfico é a necessidade de manutenção de sua casa e família.

Outrossim, subsiste nos acórdãos a ideia de que uma mãe criminosa, principalmente aquela que pratica o comércio de drogas, pode ser uma ameaça à integridade moral de seus filhos e, por isso, estes devem ser educados por outras pessoas. Contudo, sabendo-se que o tráfico é um crime que não pressupõe violência, novamente aqui se tem um julgamento que vai além da conduta realmente perpetrada, não se está analisando o risco concreto da criança, mas mais uma vez, a contaminação do ambiente e das relações pelo fantasma de determinadas drogas. Essa concepção que, a priori, coloca a mulher que comercializa droga distante da possibilidade de maternidade, está presente também no segundo caso.

\section{Caso 2}

Mulher, acusada de tráfico de drogas, com um filho de 03 anos que ainda estava em fase de amamentação, mas a família não tinha condições financeiras de se descolar até o estabelecimento para que ela pudesse alimentar a criança. Assim, pleiteava a prisão domiciliar como forma de possibilitar a amamentação, etapa imprescindível para o desenvolvimento saudável da criança. A fundamentação dos desembargadores para denegação do pedido destacou o fato da mulher traficar em casa, bem como que a apreensão da droga foi feita no quarto do menor:

Pelo que se nota da leitura das peças do flagrante realizado, é perniciosa à criança a companhia da paciente, na medida em que parcela da droga apreendida estava no próprio quarto da menor, o que revela que está, desde tenra infância, sendo levada senão ao tráfico, ao menos ao vício, pela facilitação de seus pais. (BRASIL. Tribunal de Justiça de São Paulo. Habeas corpus. Tráfico de drogas. Habeas-corpus no0077202-05.2013.8.26.0000, da $8^{a}$ Câmara de Direito Criminal, São Paulo, SP, 27 de junho de 2013). 
O julgamento pelas personagens do sistema da justiça é realizado a partir de suas próprias concepções de organização sócio familiar, muito distantes da realidade das mulheres, presas ou não, de milhares de brasileira, que encontram na traficância uma forma de complementação de renda. A realidade social desestruturada é mais um motivo, portanto, para manter o encarceramento. Toda essa complexa realidade que cerca essa mulher (moral, social e de gênero) a dissociam da figura materna e concorrem para o encarceramento, colocando-o em uma posição vulnerável frente ao sistema de justiça criminal e não ao contrário. Essa conjunção (de criminosa e mãe) não é aceito.

Contudo, conforme já se discutiu anteriormente, a mulher recorre ao tráfico de drogas por múltiplas razões, mas uma das razões mais aparentes refere-se à questão da complementação da renda familiar, ou seja, a mulher traficante é, muitas vezes, uma mulher que recorre ao mercado ilícito para prover necessidades básicas de seus filhos. No entanto, esses motivos não são considerados legítimos pelos desembargadores. Muito pelo contrário. Vê-se que a situação econômica não é só desconsiderada pelos desembargadores, mas é um motivo que as coloca no cárcere, demonstrando uma situação de extrema vulnerabilidade dessas mulheres frente à seleção do sistema de justiça criminal.

Por outro lado, a maternidade foi, em alguns julgados considerada como um fator que pudesse resgatar a mulher de sua vida criminosa, despertando princípios femininos e, que, portanto, justificariam a concessão da prisão domiciliar.

\section{$\underline{\text { Caso } 03}$}

Mulher que também havia praticado delito de tráfico de drogas e estava na $35^{2}$ semana de gestação e estava pleiteando a prisão domiciliar, mas que quando do julgamento já havia dado à luz à criança. A decisão dos julgadores foi a seguinte:

É cediço que a presença materna é importante ao desenvolvimento afetivo e emocional dos filhos menores, bem como, para prover sua assistência, fato este corroborado pela nova Lei n. ${ }^{0} 12.403 / 2011$, ao estabelecer a possibilidade de substituição da prisão preventiva por domiciliar, caso comprovada a imprescindibilidade aos cuidados de pessoa menor de seis anos de idade ou com deficiência. Ressalta-se, ainda, que a nova Lei n. ${ }^{\circ}$ 12.403/2011, em especial o artigo 318, inciso III, do CPP, aplicado ao presente, nada dispõem a respeito de qualquer vedação legal à concessão da prisão domiciliar aos acusados pela prática de crimes hediondos ou equiparados, de modo que não há óbice no cumprimento da prisão preventiva em domićlio pela paciente. No mais, espera-se que a inserção em prisão domiciliar, inspire essa mãe a adotar novos valores morais, para que possa melhor gerir suas vidas, e proporcionar a seus filhos uma vida digna. (BRASIL. Tribunal de Justiça de São Paulo. Habeas corpus. Tráfico de drogas. Habeas-corpus n0206397-77.2012.8.26.0000, da 12a Câmara de Direito Criminal, São Paulo, SP, 17 de dezembro de 2012, grifo nosso).

Aqui, ainda que a decisão seja pela concessão na prisão domiciliar, a maternidade persiste como um ideal que poderia ensejar nas mulheres novos princípios morais que as possibilitassem sair da vida do crime e, com isso, vol.09, n. 01, Rio de Janeiro, 2016. pp. 349-375 
tornarem-se boas mães, algo capaz de "salvar" essas mulheres e as fazerem cumprir com seu papel de mulher-mãe, e, portanto, uma justificativa plausível para a concessão da prisão domiciliar.

Novamente, a justificativa utilizada de que a maternidade seria capaz de salvar a mulher da criminalidade, demonstra como as representações em torno da maternidade e criminalidade são praticamente irreconciliáveis. Ou a mulher é criminosa e o sistema tira a possibilidade de ser mãe - provocando o encarceramento (em grande parte dos casos) - ou ela é mãe e o sistema espera que deixe de ser criminosa - provocando o desencarceramento com base nesta crença. Em resumo, os acórdãos analisados apontam para a construção em oposição pelos julgadores das categorias de mãe e criminosa, como categorias auto-excludentes. Essa tendência, demonstra que além dos fatores raciais e sociais que conformam a seletividade do sistema de justiça criminal, os marcadores de gênero têm um peso forte quando se trata de encarceramento feminino.

\section{INTERESSE SUPERIOR DA CRIANÇA VERSUS INTERESSE INFERIOR DA MULHER}

Outro tema caro à analise que propomos, inspirada pela perspectiva feminista (DINIZ, 2014), é que em muitos casos, o interesse superior da criança prevista na legislação ${ }^{5}$ se sobrepõe, ou mesmo, anula os interesses e direitos da mãe. Nas decisões de concessão da prisão domiciliar analisadas foi evidente que não era a presa "o sujeito de direito", mas a criança. Importante pontuar, que não está se contestando aqui a legitimidade de se atender ao interesse da criança, mas como no discurso jurídico essa defesa é feita a partir de julgamentos morais e de padrões sócio-familiares rígidos; e sob um raciocínio binário que associa à criança à pureza e inocência, em contraponto da mulher culpada. Nos acórdãos abaixo fica clara essa associação:

\section{Decisão 04}

Inegável que a recém-nascida necessita de cuidados maternos e amamentação constante, de modo que o cárcere não é ambiente mais adequado nem recomendável para uma criança de tenra idade que jamais pode ser penalizada pelos erros cometidos por seus genitores. (BRASIL. Tribunal de Justiça de São Paulo. Habeas corpus. Tráfico de drogas. Habeascorpus no0167165-24.2013.8.26.0000, da 8a Câmara de Direito Criminal, São Paulo, SP, 17 de outubro de 2013).

\section{Decisão 05}

De mais a mais, é preciso ter em mente que o interesse maior a ser tutelado aqui é o da criança, que não pode se ver privada de condições mínimas indispensáveis à sua sobrevivência. (BRASIL. Tribunal de Justiça de São Paulo. Habeas corpus. Tráfico de drogas. Habeas-corpus nº095688-38.2013.8.26.0000, da 11 1 Câmara de Direito Criminal, São Paulo, SP, 31 de julho de 2013). 


\section{Decisão 06}

Impor ao nascituro que venha à luz em um ambiente infecto será apená-lo por crime que não cometeu. (BRASIL. Tribunal de Justiça de São Paulo. Habeas corpus. Tráfico de drogas. Habeas-corpus no 0130591-02.2013.8.26.0000, da 1a Câmara de Direito Criminal, São Paulo, SP, 23 de setembro de 2013).

\section{Decisão 07}

Impõe-se observar que a nova lei deu mais importância à criança do que à punição pela prática de um crime, eis que não estabeleceu qualquer outra condição ou exigiu qualquer outro requisito, que não a prova de que a acusada possui filhos com idade inferior a 6 anos. (BRASIL. Tribunal de Justiça de São Paulo. Habeas corpus. Homicídio Qualificado. Habeas-corpus no0057045-11.2013.8.26.0000, da 16 Câmara de Direito Criminal, São Paulo, SP, 13 de agosto de 2013).

Apesar de positiva a preocupação com as crianças e a sensibilidade dos julgadores em relação ao tema, não se pode esquecer de problematizar que a justiça também deve atender aos interesses das mães, resguardando o direito das mesmas de terem uma vivência de maternidade digna. Na maior parte das argumentações, a ausência total de menção à mãe, reforça a ideia de que mulher só pode aceder ao direito por causa da criança e não por sua própria condição de mulher-mãe.

Contrariamente, os julgamentos de denegação, especialmente nos casos de imprescindibilidade da mãe para o cuidado de crianças, justificam-se, muitas vezes, no fato da prisão provocar nas filhas e filhos um desamparo familiar não é suficiente para configurar violação ao interesse superior da criança e a concessão do instituto à mulher. Como na decisão abaixo:

\section{Decisão 08}

Pese o desamparo afetivo que o encarceramento da mãe pode proporcionar aos seus filhos, a paciente não logrou demonstrar que eles necessitem de cuidados especiais ou que outros familiares ou instituições não poderiam delas cuidar (...). Embora indesejável que os filhos da paciente sejam privados de sua presença, presentes os pressupostos da custódia preventiva, tratando se de crime hediondo ou equiparado sobre o qual pesa imposição constitucional de inafiançabilidade e ausente comprovação a contento da implementação dos requisitos do art. 318 do CPP, impossível a tutela pretendida. (BRASIL. Tribunal de Justiça de São Paulo. Habeas corpus. Tráfico. Habeas-corpus no 0267559-73 2012.8.26.0000, da 13a Câmara de Direito Criminal, São Paulo, SP, 07 de março de 2013).

No julgado, o desamparo que a própria prisão causa não é tida como prejudicial à criança, apesar do ECA e da Constituição Federal preverem o direito à convivência familiar. ${ }^{6}$

Com base nestes julgamentos, conclui-se que tal interpretação pode implicar em uma limitação dos próprios direitos da criança, já que o interesse dela é pensado de forma separada (e muitas vezes oposta) do interesse de sua mãe; e a partir de parâmetros rígidos em relação à organização social e estruturação familiar. Essa 
limitação traz graves consequências para a população feminina de modo geral eis que a maior parte das mulheres presas são mães. Logo, toda essa população feminina e seus filhos ficam desemparados por uma leitura restrita e excludente das garantias individuais.

\section{CONDIÇÕES MATERIAIS VERSUS PLANO FORMAL}

Outro tema importante dos discursos dos julgadores nas decisões sobre a prisão domiciliar foi a questão da infraestrutura dos estabelecimentos prisionais para o abrigo de presas grávidas e lactantes. A situação precária das instalações prisionais é citada de uma maneira geral pela defesa das mulheres, como uma estratégia no pedido de prisão domiciliar. Em muitos casos de concessão, os desembargadores também se utilizam da falta de instalações adequadas para dar embasamento à concessão do instituto, como no caso a seguir.

\section{Caso 4}

Mulher grávida de 07 meses estava presa preventivamente desde quando foi flagrada por crime de roubo, já havendo prolação de sentença condenatória, sendo-lhe negado o direito de apelar em liberdade, justificando-se a denegação na gravidade da conduta, não levando em consideração o estágio especial na qual a mulher se encontrara.

A defesa interpôs recurso e habeas corpus pleiteando a substituição da prisão preventiva pela domiciliar, para que pudesse apelar em albergue domiciliar, com base no art. 318, inc. IV, da lei 12.403/2011, ressalvando que a mulher se encontrava recolhida em penitenciária superlotada, insalubre e desprovida de estrutura física para acolhimento de presas em estágio avançado de gravidez, sem condições para acompanhamento médico adequado e, menos ainda, para acolhimento da criança que estava por vir, sendo que sua manutenção no cárcere seria uma violação ao seu direito à saúde e aos direitos do nascituro.

A decisão favorável dos desembargadores ressaltava o caráter excepcional da medida, mas concordavam com os argumentos da defesa da falta de instalação adequada para o atendimento da presa e do recém-nascido que estava por vir e por isso, foram favoráveis à prisão domiciliar:

\section{Decisão 09}

A paciente é gestante, prestes a dar a luz a seu filho, conforme exame de fls. 46 e na esteira do quanto fundamentado pelo Procurador de Justiça, em seu parecer de fls. 55/57, os estabelecimentos penitenciários não têm tido estrutura suficiente para receber presas com bebês, de acordo com as suas necessidades. Muito pelo contrário. Os estabelecimentos prisionais, infelizmente, possuem condições impróprias para recém-nascidos, motivo pelo, excepcionalmente, concedo à paciente a substituição da prisão preventiva pela prisão domiciliar, prevista no art. 318, inciso IV, do Código de Processo Penal, expedindo-se mandado de prisão domiciliar, só podendo a paciente se ausentar de seu domicílio com autorização judicial ou mediante justificativa escrita. (BRASIL. Tribunal de Justiça de São 
Paulo. Habeas corpus. Tráfico de drogas. Habeas-corpus n0183216-13.2013.8.26.0000, da

$3^{a}$ Câmara de Direito Criminal, São Paulo, SP, 10 de dezembro de 2013).

Outro exemplo de concessão sobre uma gravidez de gêmeos, que apresentava trabalho de parto prematuro e cujo estabelecimento prisional não continha nenhum tipo de serviço para acompanhar pré-natal ou realização do parto colocou a ênfase na falta de atendimento médico adequado:

\section{Decisão 10}

Com efeito, a manutenção da paciente em estabelecimento prisional nessas circunstâncias seria colocar em risco sua integridade física. É notória a deficiência do sistema prisional brasileiro no cuidado médico dos encarcerados, até mesmo para a realização de tratamentos de rotina. A paciente necessita de cuidados pré-natais e está prestes a dar à luz duas crianças, sendo impossível prever se estas também necessitarão de cuidados médicos especiais após o parto. (BRASIL. Tribunal de Justiça de São Paulo. Habeas corpus. Tráfico de drogas. Habeas-corpus no 0143101-18.2011.8.26.0000 da 12a Câmara de Direito Criminal, São Paulo, SP, 24 de agosto de 2011)

Apesar de a decisão exemplificada focar na falta de condições para receber bebês, enfatizando a saúde da criança e não da mulher presa, houve decisões que se embasavam na falta de estrutura para atendimento médico adequado da mulher gestante.

Contraditoriamente, alguns acórdãos denegavam os pedidos de prisão domiciliar embasados na legislação que prevê a existência de estabelecimentos com estruturas capazes de satisfazer as necessidades das mulheres com seus bebês. Tais acórdãos identificam o dever-ser normativo com a realidade, como se as garantias legislativas estivessem presentes no plano material das instalações prisionais.

A Lei de Execução Penal (LEP) prevê inúmeras instalações nos estabelecimentos prisionais. Duas dessas possibilidades foram mencionadas nos discursos dos desembargadores como uma forma de negar a prisão domiciliar: - o art. 14, $\$ 3^{\circ}$ prevê que "A assistência à saúde do preso e do internado de caráter preventivo e curativo, compreenderá atendimento médico, farmacêutico e odontológico - $\$ 3^{\text {o }}$ Será assegurado acompanhamento médico à mulher, principalmente no pré-natal e no pós-parto, extensivo ao recém-nascido", bem como o artigo 89, que prevê que â penitenciária de mulheres será dotada de seção para gestante e parturiente e de creche para abrigar crianças maiores de 6 (seis) meses e menores de 7 (sete) anos, com a finalidade de assistir a criança desamparada cuja responsável estiver presa".

É o caso de uma impetração de habeas corpus pela Defensoria que pedia a prisão domiciliar de mulher gestante acusada de crime de roubo, argumentando que o estado gestacional da presa não havia sido levado em consideração na decisão de primeira instância, não havendo condições para sua manutenção no cárcere em razão do seu estado. 
Neste sentido, além da gravidade citada pelos desembargadores ser um motivo para a não concessão do instituto, a fundamentação também se deu no plano normativo da LEP, como se transcreve:

\section{Decisão 11}

No que concerne à alegação de que a paciente necessita de cuidados especiais e acompanhamento médico, em razão de gravidez, convém anotar que a Lei de Execução Penal (Lei no 7.210/84), em seu artigo 14, garante ao preso o direito de assistência à saúde, possibilitando, até mesmo, que seja atendido em estabelecimento hospitalar fora do sistema prisional (artigo 14, $\$ 2^{\circ}$ c.c. artigo 120, II, da LEP). (BRASIL. Tribunal de Justiça de São Paulo. Habeascorpus. Tráfico de drogas. Habeas-corpus no 0224822-55.2012.8.26.0000, da $14^{a}$ Câmara de Direito Criminal, São Paulo, SP, 17 de janeiro de 2013).

Essa fundamentação se torna ainda mais problemática em casos em que a mulher apresenta riscos já detectados na sua gravidez e, portanto, necessitaria de cuidados específicos, mas o discurso de denegação foca nos artigos da LEP para a não concessão do instituto.

É o que aconteceu, em um dos acórdãos investigados em que uma mulher acusada pela suposta prática de tráfico de drogas estava grávida de cinco meses, mas sofria de hipertensão arterial, caracterizando-se a situação de risco prevista na norma, a qual é agravada ainda mais por sua situação prisional. Neste caso, os desembargadores, além da justificativa da gravidade do tráfico, colocaram como ponto central para negar à prisão domiciliar com base na gestação, a menção ao art. 89 da Lei de Execução Penal, onde se prevê que os estabelecimentos penais de mulheres poderão ser dotados de seção de gestante e parturiente, além do art. $83, \mathbb{\$} 2^{\circ}$, que prevê que os estabelecimentos deverão ser dotados de locais próprios para amamentação dos recém-nascidos.

Note-se que todos os exemplos citados (de concessão e denegação) estão pautados na garantia de direitos, que é a função do judiciário e da qual não pode se eximir. Contudo, as decisões centram-se em fundamentações opostas - uma trata do plano material (ao reconhecer a inefetividade da legislação no que tange à infraestrutura dos presídios), concedendo a prisão domiciliar e desencarcerando a mulher e o outro tipo se pauta no plano formal do dever-ser normativo da LEP, tendo como consequência o encarceramento e a não garantia de direitos.

Tais fatores quando analisados mais profundamente evidenciam uma perversidade do sistema jurídicocriminal, eis que não há explicitamente uma desconsideração do estado da mulher nessas decisões que denegam os pedidos, pois os julgadores utilizam o plano formal para justificar essas decisões, pautadas na estrutura do deverser legal e, inclusive na garantia de direitos, o que permite concluir que uma análise voltada exclusivamente ao plano formal provoca o encarceramento.

\section{GRAVIDEZ NA PRISÃO: GRAVIDEZ DE RISCO?}


Ao analisar-se a lei 12.403/2011 pode-se perceber que se colocou como requisito para a concessão da prisão domiciliar, conforme já se mencionou que a mulher esteja a partir do sétimo mês de gravidez ou sendo a gravidez de alto risco.

Sobre os aspectos doutrinários que envolvem o conceito de gravidez de risco, é necessário pontuar algumas questões. Silvio Maciel (2011) aduz que o interesse da norma neste caso não é saber se a gravidez é de baixo ou alto risco, mas se o estabelecimento prisional possui instalações adequadas para os cuidados da mulher gestante, sendo que se não houver condições mínimas, a mulher deve ser imediatamente colocada em prisão domiciliar ou transferida para locais com tais condições, pois "se o presídio não tem nenhuma condição de dar tratamento para a gestante, o baixo risco tornar-se sempre alto risco.

Já Guilherme de Souza Nucci (2013) possui entendimento diverso, argumentando que o juiz somente deve autorizar a transferência ou o recolhimento do agente para sua residência nestes casos extremos, entendendo que nenhuma outra hipótese possa ser admitida. Esse mesmo autor argumenta que o benefício da prisão domiciliar não pode ser estendido a todo e qualquer réu pelo fato de que haveria falta de vagas no sistema prisional.

Apesar da argumentação de NUCCI (2013), o presente trabalho também compactua com a idéia de que uma gestação na prisão é sempre uma gestação de risco, eis que não há tratamento médico adequado para uma gestante. Sendo assim e considerando as situações materiais em que se encontram as instalações prisionais femininas no Brasil, considera-se que o magistrado deve decidir com base na situação de risco efetivo, por falta de atendimento médico.

Contudo, do universo de 80 acórdãos analisados, 10 acórdãos tratavam de hipóteses de gravidez de risco, dentre os quais apenas em metade foi concedida a medida domiciliar. Em todos os casos havia laudo médico que atestava algum perigo concreto de saúde para a mãe ou para o feto, entre eles: gestante portadora de HIV positivo, gravidez de gêmeos, quadro de trabalho de parto prematuro, hipertensão e eclampsia; bebê que veio a óbito no nascimento quando já se havia detectado o risco da gestação por médico da prisão e não se concedeu nenhum tipo de medida para evitar o acontecimento.

Veja-se que os exemplos citados são referentes acasos de provas documentais subscritas por médicos que atestaram o estado de saúde fragilizado da gestante e do feto. De forma geral, os julgadores exigem estes atestados médicos para a concessão de prisão domiciliar advinda de gravidez de risco.

Apesar da lei tratar especialmente de casos de risco de saúde, problematiza-se, nesta investigação, o fato de que as condições gerais nos cárceres femininos não propiciam um atendimento adequado da mulher à saúde reprodutiva e, especialmente no estágio de gravidez, esta falta de infraestrutura está relacionada ao não acesso destas gestantes aos exames de rotina imprescindíveis para um adequado acompanhamento da sua gravidez, 
condições materiais precárias e à inadequação geral do ambiente prisional para abrigar uma pessoa, especialmente uma mulher em período tão especial. A interpretação que retomamos aqui, já aventada em pesquisa sobre o tema (BRASIL, 2014), é que toda a gestação que ocorre dentro do ambiente prisional é, por excelência, uma gestação de risco.

A inadequação do ambiente carcerário às necessidades de saúde da gestante foi reconhecida pelos próprios desembargadores em alguns dos acórdãos aqui tratados. O relatório da Conectas realizado em conjunto com o Instituto Sou da Paz (2012) apontou para o fato de que, em todo território nacional, existiam apenas 16 médicos ginecologistas para atender as demandas dessas mulheres que compõe a massa carcerária nacional. Portanto, para que todas as mulheres obtivessem, ao menos, uma consulta por ano, cada ginecologista deveria se dedicar ao atendimento de 25 mulheres nos 365 dias do ano, fato que, obviamente, não ocorre na realidade prisional. Além do que, o mesmo relatório constatou a falta de exame pré-natal, bem como o tratamento desumanizado dispensado a estas mulheres, principalmente no transporte entre prisão e hospital.

Essa situação de risco propiciada por um ambiente de exclusão e de falta de acesso aos direitos como o cárcere é tão latente que, em um dos acórdãos sobre gravidez de risco, a concessão se deu na oportunidade em que a gestante havia sido atendida em unidade prisional, oportunidade em que foi diagnosticada com início de centralização fetal. Para o devido acompanhamento, o próprio médico da unidade sugeriu o controle fetal diário. Como se reconhece que as unidades prisionais não possuem infraestrutura para esse acompanhamento diário, a mulher conseguiu a prisão domiciliar até o término do seu período de gestação.

Contudo, apesar da concessão da medida domiciliar a esta mulher em especial, é possível se questionar que a maior parte das mulheres não possui este acompanhamento adequado, que em razão da gravidez, é necessário que seja realizado em períodos determinados: e que de forma geral, é realizado fora da unidade prisional, o que depende de disponibilidade de escolta/transporte e da escuta de suas demandas.

\section{TEMPO DE GESTAÇÃO E TEMPO DA JUSTIÇA}

Conforme se salientou, a prisão domiciliar, de acordo com a lei ora discutida, poderá ser concedida as gestantes a partir do $7^{\circ}$ mês de gravidez. De forma geral, o discurso judicial nos acórdãos analisados utiliza esse critério temporal rigidamente para determinar a concessão ou denegação dos pedidos das mulheres gestantes, ressalvando, nos casos de negativa, que a mulher não se encontra no sétimo mês de gestação. Contudo, é necessário problematizar que, muitas vezes, a análise dos pedidos ocorre muito posteriormente à impetração do habeas corpus, num momento em que a mulher já deu à luz à criança, como no caso abaixo.

\section{Caso 05}


Gestante acusada de crime de tráfico, cujo ultrassom obstétrico comprobatório da gravidez havia sido realizado quando contava com aproximadamente 30 semanas de gestação. Defensoria impetrou Habeas Corpus com pedido de prisão domiciliar. No entanto, na ocasião do julgamento do acórdão, aproximadamente quatro meses após a data do referido exame, a mulher já havia dado à luz a criança no mês anterior, fato que foi utilizado como justificativa para a denegação do pedido:

De outra parte, diversamente do alegado pelo impetrante, presentes elementos concretos autorizadores da prisão cautelar, sendo insuficientes as outras medidas diversas da privação da liberdade constantes do artigo 319 do Código de Processo Penal, mesmo porque, conforme informações colhidas, o parto já ocorreu e a paciente foi transferida ao Centro Hospitalar para o período de amamentação. (BRASIL. Tribunal de Justiça de São Paulo. Habeas corpus. Tráfico de drogas. Habeas-corpus n0183649-51.2012.8.26.0000, da 7a Câmara de Direito Criminal, São Paulo, SP, 08 de dezembro de 2012).

Ter dado à luz anteriormente ao julgamento é uma justificativa que os desembargadores utilizam para negar o pedido da defesa, ainda que o pedido tenha se dado muito anteriormente à realização do parto. Contudo, em sendo o instituto da prisão domiciliar voltado não somente às gestantes, mas também às pessoas que cuidam de criança menor de 06 anos, seria possível que o desembargador decidisse para além do postulado pela gestante, já que estaria embasado na mesma lei, possibilitando a necessária amamentação do lactante recém-nascido, o que não foi feito.

Essa postura dos julgadores traz consequências negativas relacionadas ao acesso à justiça das mulheres presas, eis que havendo a possibilidade de o julgador conceder o direito à prisão domiciliar com fulcro em outro inciso da mesma lei e não o fazendo, a encarcerada necessitaria novamente acionar o seu procurador para entrar novamente com o recurso de habeas corpus justificado na mesma lei, provocando uma dificuldade de acesso a direitos.

De outra parte, quando o pedido é feito anteriormente ao tempo previsto no plano normativo ( $7^{\circ}$ mês), justifica-se a negação do pedido por não estarem presentes as circunstâncias previstas na lei, haja vista que a mulher, hipoteticamente, não se encontra em estágio avançado de gravidez e, portanto, não está enquadrada nas hipóteses autorizadoras.

É o que ocorreu num caso onde a defesa entrou com pedido de habeas corpus em razão da mulher se encontrar no $4^{\circ}$ mês de gestação - acusada de crime de tráfico e associação ao tráfico. No entanto, a negativa deuse, justamente, pelo fato do tempo de gestação não condizer com o tempo previsto na legislação:

\section{Decisão 12}


"Quanto ao pedido de prisão domiciliar, a própria petição de impetração se incumbiu de revelar que a gravidez da paciente não está no 70 mês". (Habeas-corpus no 022655930.2011.8.26.0000, da 6a Câmara de Direito Criminal, São Paulo, SP, 12 de janeiro de 2012).

Deste modo, instaura-se a problemática do tempo de gestação, pois se o pedido ocorrer no tempo certo previsto na norma - $7^{\circ}$ mês -, devido à demora na tramitação do processo, há uma possibilidade de quando o pedido for analisado, a mulher já ter dado à luz e isto ser o motivo que irá justificar a negativa de seu pedido pelos desembargadores. No entanto, se a defesa pleitear a prisão domiciliar anteriormente ao tempo previsto na legislação, o não preenchimento dos requisitos autorizadores da concessão do instituto pela mulher não se encontrar no estágio de gravidez permitido será a justificativa no discurso dos julgadores para a denegação do pedido.

Se a mulher requer antes, tem seu pedido negado por não ter alcançado o prazo legal, se requer no prazo, corre o risco incrementado pela demora da nossa jurisdição de ter seu pedido julgado intempestivamente, quando não atende mais a condição gestante, devendo-se enquadrar-se na outra figura do art. 318 (cuidado essencial de menor de idade), cujo reconhecimento, como vimos acima, guarda uma série de empecilhos. Logo, a mulher tem exatos dois meses para pedir e ter seu pedido apreciado (do sétimo ao nono mês), sob pena de ter que protestar novamente após ter dado à luz à criança.

Essa interpretação restrita do texto legal representa mais uma dificuldade para essas mulheres a um acesso a justiça, haja vista que a morosidade do Judiciário faz com que tenham de entrar com nova ação para poder ter direito à prisão domiciliar após a gestação para alimentar o filho. $\mathrm{O}$ mesmo dispositivo poderia ser utilizado para justificar a prisão domiciliar, eis que a necessidade de amamentação é consequência da gestação e o instituto da domiciliar é cabível tanto para gestantes quanto para lactantes. Contudo, o Judiciário analisa com base apenas no pedido inicial da petição, ignorando a complexidade da questão e o desenrolar futuro da demanda, assim, a rigidez quanto a observação do critério temporal previsto em lei passa a funcionar como mais justificativa para a não concessão da domiciliar.

\section{PROVA IDÔNEA DAS CONDIÇÕES LEGISLATIVAS}

Outra questão que se faz necessária pontuar é que o parágrafo único do art. 318 do CPP exige que "Para a substituição, o juiz exigirá prova idônea dos requisitos estabelecidos neste artigo". Essa exigência legislativa dificultou a concessão do instituto, pelo que foi possível perceber nas leituras dos acórdãos analisados. Grande parte das decisões denegatóris se justifica pelo fato de que a paciente mulher não trouxe aos autos prova idônea das alegações (seja da gravidez, da gravidez de risco ou da imprescindibilidade dos seus cuidados à criança menor 
de 06 anos). Especialmente no caso de pedido de prisão domiciliar para pessoa imprescindível aos cuidados de menor de 06 (seis) anos foi essa a justificativa mais utilizada pelos julgadores para a negação do pedido da mulher.

Nestes casos, os julgadores ressaltavam que a certidão de nascimento da filha ou filho, provando a maternidade não é prova de imprescindibilidade, pois seria necessário demonstrar que a ausência da mãe teria deixado os filhos sem nenhum outro parente que lhes poderiam dispensar cuidados: além de que seria imprescindível que se demonstrasse, ainda, que a filha ou filho necessitaria de cuidados especiais, pois somente estes justificariam a concessão da prisão domiciliar.

Como a imprescindibilidade não é um critério objetivo, como o tempo de gestação ou a demonstração do estado de risco da gravidez para a saúde do feto ou da gestante (cujas provas, segundo os julgadores também deveriam ser idôneas, por meio de exame de gravidez ou laudo médico ressaltando o risco), observou-se que a demonstração do estado de risco era a justificativa mais veiculada nos acórdãos nestes casos específicos.

Outra problemática que se coloca é, sendo a imprescindibilidade um critério subjetivo, qual seria a maneira de provar isso, de forma documental, nos habeas corpus impetrados? Do ponto de vista dos desembargadores, excluindo- se o que diz a matéria doutrinária, pode-se perceber que eles não fixam, em seus acórdãos uma espécie de prova que seria indiscutível para a concessão do benefício. Isso se torna evidente porque, a maior parte dos acórdãos ressalva que a condição de maternidade não demonstra a imprescindibilidade que a mãe representa nos cuidados do filho. Contudo, por outro lado, nos casos de concessão, é comum que somente a juntada da certidão de nascimento, especialmente quando o filho é lactante, já é considerada prova idônea da imprescindibilidade da mãe. Para exemplificar:

\section{Decisão 13}

"Não comprovação da imprescindibilidade da mãe aos cuidados da criança, o qual exige prova técnica, não bastante apenas a alegação de que a paciente tem ao seu cuidado criança recém nascida".

(BRASIL. Tribunal de Justiça de São Paulo. Habeas corpus. Tráfico de drogas. Habeascorpus no0075964-48.2013.8.26.0000, da 7ª Câmara de Direito Criminal, São Paulo, SP, 18 de julho de 2013).

\section{Decisão 14}

"Inegável que a recém-nascida necessita de cuidados maternos e amamentação constante, de modo que o cárcere não é ambiente mais adequado nem recomendável para uma criança de tenra idade que jamais pode ser penalizada pelos erros cometidos por seus genitores". (BRASIL. Tribunal de Justiça de São Paulo. Habeas corpus. Tráfico de drogas. Habeascorpus n0167165-24.2013.8.26.0000, da 8a Câmara de Direito Criminal, São Paulo, SP, 17 de outubro de 2013). 


\section{Decisão 15}

"O acusado que pretenda o benefício da prisão domiciliar, haverá de demonstrar, claramente, o seu vínculo com a criança e, em particular, os cuidados especiais e imprescindíveis a ela destinados. Não basta juntar aos autos a certidão de nascimento, provando a paternidade ou maternidade; há que se demonstrar a tutela existente"; (BRASIL. Tribunal de Justiça de São Paulo. Habeas corpus. Crimes contra a vida. Habeas-corpus no0180422-19.2013.8.26.0000, da 9ª̂amara de Direito Criminal, São Paulo, SP, 07 de novembro de 2013).

Assim, o que se pode observar é a ausência de critérios para concessão/negação do pedido por parte dos próprios desembargadores que, ora concedem apenas com prova de que a paciente é mãe de recém-nascido, denegam o pedido com base no mesmo argumento. Também se pode perceber uma maior reserva por parte dos julgadores em conceder a medida domiciliar nos casos de imprescindibilidade que, quantitativamente, foram os casos em que houveram mais pedidos por parte das presas e mais denegações com essa justificativa comum de ausência de prova idônea.

Nos casos de gestação e gravidez de risco, a ausência de prova também era algo muito argumentado pelos julgadores como justificativa para a denegação, mas, como há documentos específicos e objetivos que atestam a condição de gestação da presa, caso haja a incorporação destes documentos no processo, torna-se bem difícil a negação com base nessa justificativa. Contudo, nos casos em que a presa almeja a substituição pela prisão domiciliar nos casos de crianças menores ou recém-nascidos, os julgadores podem concluir que a certidão de nascimento não é prova idônea para a concessão, bem como podem concluir o contrário, não havendo critérios objetivos, mas, na maior parte dos casos, conforme se observou na pesquisa, a tendência é a denegação do pedido quando apenas a certidão de nascimento é colacionada ao processo.

\section{O PODER DEVER: A FACULDADE DO JULGADOR}

Outro ponto pertinente para discutir-se os motivos que levam os desembargadores a negarem os pedidos de prisão domiciliar das mulheres é o argumento de que a lei não obriga a concessão da medida, ainda que objetivamente a mulher tenha se enquadrado nas hipóteses autorizadoras da concessão da medida. Segundo entendimento dos julgadores há que se analisar o caso concreto para decidir que a mulher possa permanecer em regime domiciliar. Apesar de que a análise do processo e das condições em que ocorreu o crime seja algo próprio da atividade do julgador, é necessário pontuar que essa alta discricionariedade conferida a eles por meio da lei impossibilita a concessão da medida à grande parte das mulheres que tem direito de concessão, em acordo com a lei.

Isso se torna ainda mais problemático quando a ré é processada por crime de tráfico, conforme já se ressaltou anteriormente, bem como quando há o preenchimento de todos os critérios objetivos (gestação no _vol.09, nº. 01, Rio de Janeiro, 2016.pp. 349-375 
tempo correto, gestação de risco ou imprescindibilidade), mas, por conta da política altamente repressora do estado, os julgadores utilizam-se do seu arbítrio conferido pela lei e acabam por negar a medida às mulheres que objetivamente teriam direito à domiciliar. E esse poder (arbitrário - discricionário) é citado nos acórdãos como justificativa para a denegação:

\section{Decisão 16}

"Ademais, o preceito legal em questão prevê que o Juiz "poderá"substituir a prisão preventiva pela domiciliar nessa hipótese, não se tratando, dessa forma, de um poder-dever do Magistrado, já que necessária à análise do caso concreto. (BRASIL. Tribunal de Justiça de São Paulo. Habeas corpus. Tráfico de drogas. Habeas-corpus nº18798649.2013.8.26.0000, da 2a Câmara de Direito Criminal, São Paulo, SP, 09 de dezembro de 2013)".

\section{Decisão 17}

"A utilização do verbo poder ao invés de dever, tem o significado de que cabe ao magistrado a análise de cada caso específico para identificar a conveniência e razoabilidade da substituição da custódia processual em estabelecimento penal pela prisão processual na forma domiciliar. (Nesse sentido Guilherme de Souza Nucci, em Prisão e Liberdade, pág. 78, RG, São Paulo). E para tanto o julgador deverá confrontar o bem jurídico que se tutela pela retirada do acusado do cárcere (as razões humanitárias da medida no caso concreto) com os motivos da prisão processual (os fatos que revelam a necessidade da privação da liberdade). Deve-se, portanto, averiguar se o direito tutelado é proporcional ao risco decorrente da redução do controle à liberdade do preso. (BRASIL. Tribunal de Justiça de São Paulo. Habeas corpus. Tráfico de drogas. Habeas-corpus 0196474- 27.2012.8.26.0000, da $6^{a}$ Câmara de Direito Criminal, São Paulo, SP, 13 de setembro de 2012)".

Deste modo, o verbo "poder" na lei leva os desembargadores ao entendimento de que eles não possuem o "dever" de conceder a prisão domiciliar nos casos em que há o preenchimento das hipóteses, o que lhe dá ampla liberdade para priorizar outros aspectos que envolvem o caso concreto do que a vivência de uma maternidade e gravidez segura para a mulher e, essa priorização de outras exigências é observada na maior parte dos casos.

\section{PRISÃO DOMICILIAR VERSUS OUTRAS MEDIDAS CAUTELARES}

Em termos gerais, os julgadores não aplicam o art. 319 do CPP para concessão de medidas cautelares diversas da prisão. A prisão domiciliar é um instituto que auxilia as mães a vivenciarem a maternidade em um ambiente mais propício do que o cárcere e evita o paradoxo apresentado pela pesquisa Dar à luz na sombra (Brasil, 2014) entre a institucionalização da criança e a separação da mãe, sendo a medida mais adequada quando a finalidade é a conjugação dos direitos das crianças e das mulheres de vivenciarem a maternidade. 
No entanto, como as mulheres em questão são, em sua maioria, pobres, a domiciliar não é a medida que é mais compatível com a condição socioeconômica das mulheres que a pleiteiam: muitas delas não têm domicilio, e a maioria, só tem a própria força de trabalho como fonte de renda.

Muitas vezes, os pedidos relacionados à prisão domiciliar são negados com base no fato de que a mulher traficava em sua própria residência, o que implicaria um desmerecimento por parte desta ao instituto, conforme se segue:

\section{Decisão 18}

"Ademais, segundo os autos, a paciente guardava o entorpecente em sua própria casa, o que torna temerária a concessão da ordem para seu retorno, pena de desacreditar o instituto, benefício excepcional a ser concedido de forma criteriosa, á luz das circunstâncias do caso concreto". (BRASIL. Tribunal de Justiça de São Paulo. Habeas corpus. Tráfico de drogas. Habeas-corpus no 0267559-73.2012.8.26.0000, da 13ª Câmara de Direito Criminal, São Paulo, SP, 13 de março de 2012).

Sob essa perspectiva, se a residência da mulher foi local para o tráfico de entorpecentes, ela não mereceria a concessão do instituto. No entanto, para dar sustento à família, precisaria sair de casa para trabalhar, além de que os cuidados que uma criança pode fazer com que ela necessite sair de casa o que traria complicações ao regime domiliciliar. Assim, a burocratização e seletividade da concessão da prisão domiciliar, faz com que apenas aquelas mulheres que reúnem condições materiais e familiares mais favoráveis tenham acesso ao instituto, reproduzindo assim a seletividade do sistema penal.

A possibilidade de conceder medidas cautelares diversas, no entanto, não é uma consideração dos julgadores, tampouco da defesa, que se coloca, primeiramente, pela concessão da liberdade provisória para, após, pleitear a prisão domiciliar, como se fossem os únicos institutos que a lei 12.403/2011 trouxesse em benefício dos encarcerados de forma geral.

A preocupação com esse fator foi, dentre todos os acórdãos analisados, encontrada em apensas em uma decisão e não por iniciativa da defesa, mas por concessão dos próprios desembargadores que mostraram certa sensibilização com o caso. Apesar dessa notável sensibilização, ressalta-se, mais uma vez, que foi apenas em uma decisão, sendo que em todas as outras, essa preocupação foi inexistente, tanto dos julgadores, quanto por parte da própria defesa.

O caso especial refere-se a uma mulher acusada de tráfico de drogas, que possuía, além de três filhos menores 06 anos de idade, seu pai sexagenário como dependente, haja vista que o mesmo estava impossibilitado de se locomover por em razão da avançada idade. Além disso, a mãe da paciente comprovou que os netos estavam sob sua responsabilidade, no entanto, o salário que recebia como empregada doméstica somente conseguiria prover as necessidades do marido, não dos netos. Diante dessa situação peculiar, a defesa pleiteou a liberdade 
provisória, ou alternativamente, a prisão domiciliar. Contudo, o julgamento dos desembargadores responsáveis colocou a problemática da prisão domiciliar e deferiram outras medidas cautelares. Segue a decisão:

\section{Decisão 19}

Sabe-se que os menos favorecidos pela sorte encontram maiores dificuldades para demonstrar certas evidências, especialmente quando haja necessidade de comprovar os dramas domésticos. Por isso, a prova pré-constituída que a Dra. Defensora conseguiu produzir não pode ser sumariamente ignorada, devendo servir para abonar o quanto foi sustentado na inicial desta impetração (...). A partir daí, justifica-se, inda que excepcionalmente, a substituição da ordem de prisão por medidas cautelares não detentivas, para que a paciente retorne ao ambiente familiar e cumpra o seu dever de filha e mãe. Descarta-se, no caso, a prisão domiciliar, que não seria conveniente por mais de uma razão (uma delas, talvez a principal, a circunstância de não serem permitidas saídas da residência sem autorização judicial, quando se presume que para cuidar dos filhos a mãe tenha que se locomover para fora de casa com relativa frequência (...). Defere-se, portanto, a substituição da prisão preventiva pelas seguintes medidas cautelares previstas no art. 319 do Código de Processo Penal, de cumprimento obrigatório sob pena de revogação e recondução da paciente ao cárcere:

i. Comparecimento aos atos do processo e comparecimento mensal em juízo, para informar e justificar suas atividades, especialmente no cuidar dos filhos;

ii. proibição de acesso ou frequeência a bares e outros lugares onde haja consumo de bebidas alcoólicas e sejam conhecidos como freqüentados por usuários de drogas;

iii. proibição de ausentar-se da Comarca do Guarujá sem autorização judicial:

iv. recolhimento domiciliar no período noturno durante o andamento do processo.(BRASIL. Tribunal de Justiça de São Paulo. Habeas corpus. Tráfico de drogas. Habeas-corpus no 0290000-82.2011.8.26.0000, da 2a Câmara de Direito Criminal, São Paulo, SP, 27 de fevereiro de 2012).

Esse julgamento só foi possível graças às circunstâncias muito especiais que envolviam o caso. Circunstâncias que certamente não fariam com que a prisão domiciliar fosse um instituto suficiente para que a mulher pudesse realmente exercer sua maternidade, pois, precisaria se ausentar de sua residência para suprir as demandas das filhas e filhos.

Contudo, novamente coloca-se o ideal seria que a defesa pudesse sempre pedir, além da prisão domiciliar, medidas cautelares outras que não fossem prisão, a fim de buscar o melhor interesse das mulheres, bem como os institutos mais favoráveis às rés.

\section{CONCLUSÃO}

A análise dos acórdãos nos permitiu observar como o exercício de direitos ligados à maternidade das mulheres em situação prisional é obstaculizado e negligenciado pelos chamados operadores do direito. Ao colocarem a pretensão punitiva no primeiro plano, provocam violações a direitos maternos garantidos pela legislação às mulheres presas. 
De modo geral, podemos afirmar que as concessões de prisão domiciliar só são viabilizadas quando há riscos de saúde extremos para as mulheres e, em alguns casos em que há condições precárias no estabelecimento prisional e a mulher já se encontra em estado avançado de gestação. Já nos casos de concessão, há sempre a necessidade de frisar o caráter excepcional da medida na decisão, especialmente quando a conduta perpetrada pela mulher era a do tráfico de drogas. Por isso alguns pontos foram centrais para entender os casos que os julgadores viabilizam ou inviabilizam as concessões de prisão domiciliar.

Um desses casos evidenciados pela pesquisa mostrou como o apego ao plano formal da lei influencia negativamente as decisões relacionadas às gestantes/mães que pleiteiam a prisão domiciliar como forma de fugir dos riscos que uma maternidade na prisão representa. Primeiramente, verificou-se que a rigidez quanto ao aspecto temporal da lei 12.403/2011 (a partir do 70 mês de gravidez) é um fator que dificulta enormemente o acesso à justiça para essas mulheres, pois a morosidade das análises dos pedidos faz com que mulheres que pleiteiam a prisão domiciliar no tempo correto tenham seus pedidos analisados, muitas vezes, em período posterior ao parto, o que se torna a justificativa dos julgadores para a não concessão pelo não enquadramento da mulher à hipótese da lei. Contudo, contrariamente, quando a mulher pleiteia antes de dado o sétimo mês, o argumento é de que não se encaixa nas hipóteses autorizadoras.

Ainda com relação ao apego ao plano formal, problematizou-se que as negações são, muitas vezes, justificadas pelas previsões da Lei de Execução Penal relacionadas à necessidade que os estabelecimentos prisionais possuam instalações adequadas para gestantes e mães. De outra parte, as análises com base no plano material são feitas como modo de viabilizar a concessão da prisão domiciliar. Com isso, pode-se visualizar que uma análise amparada apenas no plano formal visa o encarceramento e a não concessão dos institutos benéficos às mulheres. Isso pode ser compreendido porque uma análise no plano material irá problematizar a inefetividade da legislação garante de boa estrutura nos estabelecimentos prisionais, não tendo outra possibilidade a não ser conceder a prisão domiciliar a fim de garantir direitos mínimos de saúde reprodutiva às encarceradas.

As condições materiais dos estabelecimentos prisionais como justificativa para a concessão da prisão domiciliar é uma hipótese trazida pela própria lei, cujo propósito foi o de garantir a gestação saudável da mulher.

Nesse sentido, como antes citado, não interessaria saber se a gravidez é de baixo ou alto risco, eis que com a gestação há a necessidade intrínseca de estrutura adequada, atendimentos médicos facilitados e um ambiente adequado, por isso qualquer gestação na prisão seria de alto risco. Portanto, para que haja uma efetivação de direitos é fundamental que os julgadores estes tomem suas decisões com base na realidade material, o que na maior parte das vezes não acontece. Assim, se uma gravidez não é comprovadamente de risco, mas o estabelecimento prisional não possui as instalações adequadas, a gravidez torna-se de risco e, por isso, justifica a concessão com base no risco, já previsto em lei. Se assim fosse considerado, a maior parte dos pedidos teria, 
necessariamente de ser concedidos, tendo como perspectiva que a maior parte das instalações prisionais brasileiras não é apta para satisfazer as necessidades da mulher, tampouco da criança.

Os efeitos da rigidez do plano formal também incidem sobre as dificuldades de acesso à justiça dessas mães, pois a rigidez ao tempo requerido pela lei para a concessão da prisão, aliado à morosidade da justiça faz com que muitas presidiárias com 7 meses de gestação tenham seus pedidos analisados em período posterior ao parto, sendo que os pedidos que são feitos anteriormente à esse prazo são denegados com a justificativa de que não houve, por parte da mulher, o cumprimento das condições legislativas.

Alguns outros pontos também foram chave para se entender os motivos que levam os julgadores a não conceder o instituto. A subjetividade da expressão imprescindibilidade é um fator que contribui para que não haja um critério rígido que determine o que pode se considerar imprescindível e o que não é. Isso é emblemático porque, ao passo em que algumas decisões consideram que o simples fato de uma mulher ser mãe de um recémnascido ou criança já a torna imprescindível aos seus cuidados. Contudo, muitas das decisões não consideravam a maternidade como sinônimo de imprescindibilidade e requeriam as provas de que o cuidado da mulher para a criança seria imprescindível, o que denota o caráter amplamente subjetivo desta expressão, dando arbítrio ao julgador para conceder unicamente nos casos em que the parecer correto.

De maneira semelhante, a rigidez com que se trata prova das condições legislativas para concessão do instituto é um apego dos magistrados para, na maior parte dos casos, justificar uma não concessão. Assim, pede-se da mulher a prova da "imprescindibilidade", do tempo da gestação, do laudo médico para comprovação do risco que a permanência no estabelecimento prisional pode representar para a gestação.

Outro fator problemático para a concessão da medida foi o crime que as mulheres cometiam: o tráfico de entorpecentes, na maior parte dos acórdãos analisados. A dinâmica do tráfico, como já dito anteriormente prejudica as mulheres, eis que a elas são destinados os papéis menos importantes dentro dessa estrutura. Assim, são mais vulneráveis à seleção das instâncias de controle formal do sistema de justiça criminal do que os homens. Como também são responsáveis pela dimensão biológica e social da reprodução, vivenciando a maternidade e posteriormente, a criação dos filhos, a extrema rigidez com que o Estado trata o fenômeno de venda de entorpecentes é um fator de fundamental importância para entender os altos índices de encarceramento feminino e a conseqüente desconsideração do estado da mulher na concessão de institutos benéficos pelos julgadores, como é o caso da prisão domiciliar. Houve uma evidente reserva nas argumentações dos desembargadores na concessão da prisão domiciliar para traficantes, tendo como argumento o caráter de equiparação à crime hediondo do tráfico. Esse tratamento pode ser lido, através de uma perspectiva de gênero, como discriminatório em relação à mulher. 
E, por último, evidenciou-se a incompatibilidade das categorias de mãe e criminosa (principalmente traficante) para os julgadores que, nas denegações, justificavam-se pela influência negativa que a mulher representaria para os filhos, tendo como base seu comportamento criminoso ao traficar entorpecentes e, por isso, não poderia ser beneficiada tendo como argumento sua maternidade ou gestação. De outra parte, algumas concessões embasavam-se na esperança de que a vivência da maternidade despertasse princípios morais da mulher, afastando-a do mundo do crime. Assim, para o sistema de justiça criminal, ou a mulher é criminosa e o sistema retira a oportunidade de vivenciar a maternidade, ou a mulher é mãe e o sistema irá conceder a prisão domiciliar na espera que não seja mais criminosa. Esse tipo de argumentação/decisão evidencia o caráter patriarcal e discriminatório do sistema de justiça criminal em relação à mulher, que não é julgada apenas por sua conduta, mas também pelos rompimentos dos papéis de gênero imposto, os quais ela deveria desempenhar para que sua maternidade fosse reconhecida e respeitada.

Assim, pode-se concluir que a mulher selecionada pelas instâncias de controle formal possui, de forma geral (e partindo-se do pressuposto que irá romper com as expectativas de que a maternidade a salve de cometer novas condutas problemáticas uma maternidade subalterna em relação às outras mulheres, estando na base da pirâmide reprodutiva hierárquica, tendo o comprometimento de seus direitos humanos pelo sistema de justiça criminal.

\title{
WHEN HOME IS THE PRISON: AN ANALYSIS OF DECISIONS OF PRISON HOUSEHOLD OF PREGNANT AND MOTHERS AFTER THE LAW 12.403 / 2011
}

\begin{abstract}
This article is the result of search for "Criminal Justice System and the exercise of motherhood for women in prison situation - an analysis of the role of justice on the ensuring pregnant and mothers prisoner's rights, and had for object of study and analysis the way as issues related to the execution of pregnant prisoners rights and mothers are being treated by the criminal justice system. Whereas the Brazilian legal system governs so specifies the maternal and child rights, we seek to understand, through the TJ / SP Case analysis, as has been the realization of rights of pregnant women and mothers arrested by the judges. The focus of the research was the application of house arrest Institute brought by Law 12.403 / 2011 in cases of pregnancy and motherhood. Analysis of judgments allowed the conclusion that the decoupling of the criminal woman - mainly drug dealer - and motherhood produces a negative discrimination, eventually influence the negative granting beneficial institutes brought by the law in question.
\end{abstract}

Keywords: female incarceration - house arrest - law 12.403/2011 - pregnant women - mothers.

\section{REFERÊNCIAS BIBLIOGRÁFICAS}


BRASIL. Ministério da Justiça. Secretaria de Assuntos Legislativos. Dar à luz na sombra: condições atuais e possibilidades futuras para o exercício da maternidade por mulheres em situação de prisão. Ministério da Justiça, Secretaria de Assuntos Legislativos. Brasília: Ministério da Justiça, IPEA, 2015. Disponível online: http://participacao.mj.gov.br/pensandoodireito/wp-content/uploads/2015/03/51-Dar-a-luz-na-sombra.pdf. Acesso em: maio de 2015.

Ministério de Justiça. Departamento Penitenciário Nacional: dados gerais mulheres presas. Infopen Estatística. Brasília: 2011. Disponível em:< www.mj.gov.br/depen>. Acesso em: nov. 2014.

Ministério da Justiça. Secretaria de assuntos legislativos. Excesso de prisão provisória no Brasil: um estudo empírico sobre a duração da prisão nos crimes de furto, roubo e tráfico. Ministério da Justiça: Brasília, Ministério da Justiça, IPEA 2015. Disponível em: http://pensando.mj.gov.br/wpcontent/uploads/2015/05/rog\%C3\%A9rio_finalizada_web.pdf acesso em: ago. 2015

CHERNICHARO, L.P; PANCIERI, A. C; SILVA, B. B. M. Mulheres encarceradas, seletividade penal e tráfico de drogas no Rio de Janeiro. GT - Sistema Penitenciário e Direitos Humanos. Anais do VII I Encontro da Andhep, 2014.

CONECTAS, Direitos Humanos. Penitenciárias são feitas por homens e para homens. Disponível em: $<$ http://carceraria.org.br/wp-content/uploads/2012/09/relatorio-mulherese-presas_versaofinall.pdf > Acesso em: ago, 2014

DINIZ, Débora. Perspectivas e articulações de uma pesquisa feminista. Florianópolis: Ed. Mulheres, 2014.

HELPES, Sintia Soares. Vidas em jogo: um estudo sobre mulheres envolvidas com o tráfico de drogas. São Paulo: IBCCRIM - Instituto Brasileiro de Ciências Criminais, 2014

INSTITUTO SOU DA PAZ. Relatório da pesquisa Prisões em Flagrante na cidade de São Paulo. Instituto Sou da Paz: São Paulo, 2012. Disponível em: http://www.soudapaz.org/upload/pdf/justica_prisoesflagrante_pesquisa_web.pdf acesso em: ago. 2015.

INSTITUTO TERRA, TRABALHO E CIDADANIA E PASTORAL CARCERÁRIA. Relatório da Pesquisa Tecer Justiça - presas e presos provisórios na cidade de São Paulo. ITTC: São Paulo, 2012. Disponível em: http://carceraria.org.br/wpcontent/uploads/2013/02/rel_tecer_justic\%CC\%A7a_net.pdf Acesso em: ago. 2015.

JESUS, M. G. M; OI, A.H; LAGATTA, P; ROCHA, T.T. Prisão Provisória e Lei de Drogas - um estudo sobre os flagrantes de tráfico de drogas na cidade de São Paulo”. Núcleo de Estudos da Violência: Universidade de São Paulo, 2011. Disponível em: http://www.nevusp.org/downloads/down254.pdf Acesso em ago. 2015.

LEMBRUGER, J; FERNANDES, M. Impacto da assistência judiciária a presos provisórios - um experimento na cidade do Rio de Janeiro. Associação pela Reforma Prisional: Rio de Janeiro, 2011. Disponível em: https://redejusticacriminal.files.wordpress.com/2013/07/cesec-arp-impacto-da-assistencia-juridica-a-presosprovisorios-2012.pdf Acesso em: ago. 2015.

MACIEL, Silvio. Capítulo IV. Da prisão domiciliar. In: GOMES, Flavio Luiz; MARQUES, Ivan Luiz (Coord.). Prisão e Medidas cautelares. Comentários à Lei 12.403, de maio de 2011.2.ed. revSão Paulo: Reviunata dos Tribunais, 2011. 
MOURA, Maria Juruena. Porta fechada, vida dilacera - mulher, tráfico de drogas e prisão: estudo realizado no presídio feminino do Ceará. Dissertação de Mestrado. Programa de pós-graduação em Políticas Públicas e Sociedade. Universidade Estadual do Ceará. 2005

NUCCI, Guilherme de Souza. Manual de Processo Penal e Execução Penal. 10.ed. São Paulo: Revista dos Tribunaus, 2013.

SOARES, Bárbara, ILGENFRITZ, Iara. Prisioneiras: vida e violência atrás das grades.Rio de Janeiro: Garamond. 2002

Trabalho enviado em 14 de setembro de 2015.

Aceito em 28 de outubro de 2015. 